\title{
TEFL Tourism: The Tourist Who Teaches
}

\section{$\underline{\text { Abstract }}$}

There is evident lineage between the concepts of teaching English as a foreign language (TEFL) and tourism, represented through evocative marketing material, the commoditisation of the TEFL product, teacher motivations and experiences. Yet, to date there has been little attention paid to this relationship. The amalgamation of the two concepts brings rise to the introduction of the niche form of tourism 'TEFL tourism', where the tourist travels outside of their usual environment to teach English as a foreign language and whose role shifts between tourist, educator and educatee at various points in their trip. The TEFL tourism phenomenon is explored through the use of a two-phase research approach employing the qualitative examination of blogs written by TEFL teachers and quantitative surveys. Drawing parallels with associated tourism forms including volunteer, education and philanthropic, it is concluded that TEFL tourism is an entity in its own right, with unique characteristics and motivations presented by TEFL tourists. The use of logistic regression facilitated the analysis of TEFL teacher types, presenting a typology classifying tourists as leisure-minded; philanthropy-minded; career-minded; expatriate-minded. This case-study examination facilitates initial comprehension of the TEFL tourism industry, providing basis for subsequent research to be undertaken to enable enhanced sustainable management of the TEFL industry worldwide.

\section{$\underline{\text { Keywords }}$}

TEFL tourism, education, volunteer, philanthropy, sustainability 


\section{Introduction}

The tourism industry is a broad and dynamic sector that is continuously evolving in accordance with consumer demands and preferences. The emergence of many niche forms of tourism have changed the face of the sector, moving progressively away from the traditional associations with sea, sun and sand motivations and destinations (e.g. Poon, 1993), along with the homogenous and standardised nature of Fordist mass production (e.g. Boorstin, 1964; Butler, 1980; Poon, 1993), to a diverse and dynamic industry. Tourists have developed as consumers, becoming increasingly sophisticated in their needs and preferences as a result of this emergent culture of tourism (Robinson and Novelli, 2007), evident through the abundant opportunities available in today's market.

TEFL tourism is a niche tourism form that encompasses notions of both education and tourism. It can be argued that the teaching English as a foreign language (TEFL) industry is one of the largest in the world. According to the British Council, as of 2014 the number of English language learners worldwide is 1.5 billion and it is estimated that this figure will increase to over 2 billion by 2020 . This has generated an almost insatiable demand for TEFL teachers, and the lack of qualified English instructors presents one of the largest challenges to educators and citizens across the globe. It is estimated that 250,000 native English speakers work as English teachers in more than 40,000 schools and language institutes around the world (International TESOL Association, 2014), although this figure may be significantly higher as a result of employment unaccounted for by the state such as private tuition or those working without the correct visas or paperwork.

As a result of this demand for English teachers, coupled with the popularity of the gap year phenomenon, voluntary work, CV building and the desire to 'do something different', there 
has been a boom in the number of TEFL tourists across the globe. Based upon this research A TEFL tourist can be defined as 'a person who travels outside of their usual environment to teach English as a foreign language, whose role shifts between tourist, educator and educatee at various points in their trip'. Ironically, there have to date been no associations made between the concepts of TEFL and tourism, yet a simple Internet search for TEFL opportunities, particularly in destinations renowned for tourism, presents the reader with evocative images of leisure options such as beaches, animals and the local nightlife scene. This paper therefore draws ties between these industries, subsequently introducing the concept of TEFL tourism.

\section{Literature}

The burgeoning globalisation of the world economy has seen societal English speaking capabilities increase in importance throughout many countries (Graddol, 2014; Griffith, 2014). Similarly to other associated industries such as volunteer, responsible or sustainable tourism however, the focus has in many cases shifted away from its traditional altruistic and philanthropic perspective, where education was the priority, to a post-modern commercialised commodity, acting as a resource that can be produced, controlled, distributed and valued (Lavankura, 2013). Weaver (2014) argues that alternative forms of tourism, such as TEFL tourism, have begun to converge with the mass market. This is demonstrated for example through the significant increases in the number of commercial operators that have subsequently changed the face of the volunteer tourism industry (Wearing and McGehee, 2013b), where it is suggested that the ideological foundations have become threatened in exchange for a profit-driven industry (Mostafanezhad, 2013). 
Whilst there is not yet any existing literature addressing the TEFL industry in this way, lessons can be learnt from the volunteer market. Existing literature addressing the volunteer tourism industry is predominantly utilised as a means of framing this study due to the scale and extent of existing research in this field as opposed to other alternative forms. The past two decades have seen the industry manifest in a range of contexts and progressively move away from being a micro to a macro niche (Stainton, 2016; Wearing and McGehee, 2013a). Whilst the study of TEFL tourism may classify as a micro volunteer tourism niche on many accounts, taking into consideration current debates regarding the blurring of boundaries and paid work (e.g. Ellis, 1997; Lyons, 2003; Lyons and Wearing, 2012; Tomazos and Butler, 2009) and the extent of unpaid opportunities, it is argued that such micro niches should be examined individually as opposed to adopting the current umbrella approach (Stainton, 2016).

Similar to many volunteer tourism packages, examination of TEFL organisations advertised on the Internet presents parallels in many ways with the traditional travel agent, acting as post-modern tour operators that have moved beyond the traditional stereotype of the package holiday (Stainton, 2017; Vainikka, 2014). Many programs offer travel advice and orientation prior to departure, in-country transportation, accommodation and visa assistance. In addition, some programs offer optional excursions such as orphanage tours. There are a range of TEFL organisation types ranging from charitable, governmental or nonprofit to commercial ventures (Griffith 2014). The prolific nature of the industry however can be demonstrated for example through the company named i to i, who offer TEFL placements as part of their provision, and despite their individual branding are owned by the profit-maximising organisation First Choice Holidays (Benson and Wearing, 2012). It is 
therefore perhaps no surprise that TEFL teaching opportunities provided by such agents have such strong associations with the traditional package tourism model.

The nature of TEFL varies significantly across geographical locations, educational institutions and employers or placement organisers. Placements may be based in the teacher's home country or abroad, can involve varying levels of teaching and can be paid or voluntary. Placements can be self-sourced or organised through the use of an agency such as a charity or for-profit tour operator (Griffith, 2014). Currently, the industry is predominantly unregulated (Griffith, 2014; Kogar, 2014), and it can be argued that providing an objective account of the TEFL sector to facilitate global regulation may be an impossible task as a result of its extreme diversity. There are a number of ambiguities within the industry that may cause confusion for TEFL stakeholders, for example there is no specific job description of a TEFL teacher, there are no regulations with regards to pay, and there is no universal person specification or qualification requirements. It is questions such as these that result in the existing grey dynamics of the global TEFL industry.

The TEFL teacher can be classified a tourist on two accounts. The first is the movement from their usual place of residence, to their TEFL destination. Although some TEFL teachers may undertake employment for periods over one year, a determining criteria defined by the WTO and UN (1994), due to the nature of temporary residency permits and frequent incountry relocation by tourists, along with the other definitions that do not impose time restrictions (e.g. Leiper, 1979; Matheison and Wall, 1982), this can be classed as a tourist experience. The second justification is that many TEFL teachers undertake day-trips or short breaks both within and outside of their TEFL country. Effectively therefore it can be argued that they are 'tourists within tourists'. This is in line with the work-leisure binary that can be 
found in the tourism and hospitality literature by focusing on Western, privileged,

voluntarily mobile employees (i.e., backpackers, at ski resorts) who both work and consume the outputs of colleagues (Duncan et al, 2012).

There are a number of tourism forms that are either encompassed within, or related to TEFL tourism. One of its closest allies in the current literature is the volunteer tourism industry, where the focus is on those tourists who undertake holidays involving volunteering to aid or alleviate material poverty, restore environments or research aspects of society or the environment (Wearing, 2001). Whilst TEFL tourism may sit below the volunteer tourism umbrella in some instances, in others it may not. This is particularly relevant to the association with payment, where volunteer tourists have traditionally been associated with a lack of monetary compensation for their efforts (Brudney, 2000; Wearing, 2001). Whilst there are arguments that the blurring of paid and voluntary work has become commonplace (Lyons and Wearing, 2012), for many scholars the TEFL teacher who is in receipt of a regular salary will not qualify as a volunteer tourist. Furthermore, as a result of the exponential growth and diversification of the industry (Coghlan and Fennell, 2009; Wearing and McGehee, 2013b) it has been argued that there is a need for segmented examination in to the specific sectors, such as TEFL, as opposed to the broad research approach that tends to have been taken to date (Stainton, 2016). It must also be noted that there are similarities with backpacking tourism and working holidays although there appear to be no direct links in the existing body of literature.

The TEFL tourism industry also demonstrates notions of philanthropy, which in the context of tourism can be defined as the donating of money, in-kind resources, or time occasioned by or facilitated by travel (Goodwin et al, 2009). It has been argued that philanthropy is a 
niche in tourism, but to a similar extent tourism is a niche in philanthropy (Bergman, 2013) and despite having strong foundations within many forms of tourism (e.g. disaster, volunteer, eco), it remains significantly under-researched (Novelli et al, 2015). Also termed philanthrocapitalism (Edwards 2009), strategic corporate philanthropy demonstrates some parallels with TEFL tourism. Often utilised as a means to enhancing ones competitive identity and social engagement (Hero, 2001; McAlister and Ferrell, 2002), it is argued that many benevolent intentions are underpinned by enhanced commercial prospects such as promotion of their brand image or increased prospects to work with sponsors, as opposed to the cause they are claiming to support (Porter and Kramer, 2002). This same notion can be applied to tourists who exhibit motives such as career development (Coghlan and Fennell, 2009; Daldeniz and Hampton, 2011; Soderman and Snead, 2008) or who undertake philanthropic endeavours as part of a course requirement (Daldeniz and Hampton, 2011; Lyons, 2003), where helping others is secondary to the personal benefits they receive. This notion has been subjected to particular debate within the volunteer tourism literature where the altruistic intentions of tourists have come under increasing scrutiny (e.g. Brown and Morrison, 2003; Callanan and Thomas, 2005; Coghlan and Fennell, 2009; Daldeniz and Hampton, 2011; Mustonen, 2005; Wearing and McGehee, 2013b). As such it can be suggested that while the practice of TEFL may appear philanthropic, this may not always be the case.

Arguably most central to the TEFL experience is education. The TEFL teacher can qualify as an educational tourist in two respects: they are educated through their TEFL experience, whether formally or informally, and they are the educators. There is little academic literature addressing the concept of educational tourism and its conceptual foundations (Falk et al, 2012; Ritchie et al, 2003; Stone and Petrick, 2013; van't Klooster et al, 2008), and 
any existing research focusses the education that the tourist receives as opposed to the education that they provide. Within the TEFL experience there are two clear distinctions between the types of tourist learning that takes place; formal (e.g. TEFL courses, teacher training) and informal (e.g. learning through travel or cultural immersion). Accordingly, Ritchie et al (2003) suggest that the educational tourism industry should be segmented. The first proposed segment is university, college and school tourism, in which the tourist experience is secondary to formal learning and can be described as education first. The second is edu-tourism, defined as general travel for education and known as tourist first (Ritchie et al, 2003), although, it is difficult to measure whether educational benefits are the results of travel, interaction with other cultures, classroom study or a combination (Abrams, 1979).

The TEFL industry is a geographically and culturally diverse industry, and as such associated tourism forms will inevitably differ according to the context within which the TEFL tourist is situated. This paper presents data collected from a case-study focussing on TEFL tourism in Thailand. As a result, there were strong notions of cultural tourism, where TEFL teaching provides access to culture in two regards; undertaking excursions to cultural sites such as temples or museums; community engagement whilst working in a Thai educational establishment. There were also strong notions of nightlife tourism, also referred to as the late night economy, consisting of the likes of all-night parties, alcohol, illegal substances and sex (Calafat et al, 2010) and the paradigms of sex tourism (Ryan, 2000).

\section{Methods}

The research was a phenomenological enquiry, placing peoples' lives and lived experiences as central to understanding what 'being in their [TEFL] world' was like (Seale, 2012). Data 
was inductively interpreted in order to obtain a holistic view of the TEFL experience through a two-staged mixed methods research approach, employing qualitative blog analysis and quantitative surveys as methods of data collection. The mixed-methods approach allowed for greater validity, with the two research paradigms facilitating a corroboration of the data collected (Bryman, 2006; Creswell, 2003) and allowing for the weaknesses of each method to be offset by the other (Bryman, 2006).

Blog analysis facilitated the preliminary exploratory phase of the research, providing datarich and valuable information in areas that had not been previously addressed in the academic literature (Banyai and Glover, 2012; Stainton, 2017). Some go so far as to describe this contemporary research method as 'the new guardians of democracy, a revolutionary form of bottom-up news production' (Hookway, 2008 91) as bloggers are free to upload a range of content of their choice, making this data source unique in that it is not in any way influenced by the researcher, deriving from naturally occurring, communal, cross-consumer interaction that is not found in alternative research methods (Meged et al, 2014). This research took the view that the blogs analysed were published in the public domain, and therefore there was no need to request consent (Snee, 2013; Stainton and Irodanova, 2016).

Data were obtained through a combination of purposive and snowball sampling techniques and blogs were located through the search engine Google and Wordpress blogging platform. Only blogs that addressed motivations, experiences or characteristics of TEFL teaching in Thailand and were written by past/current/present TEFL teachers were considered for the research. Snowballing was facilitated through the use of hyperlinks included with blogs. A total of 36 blogs were collated, after which time the determined saturation point was 
reached. This sample was considered to be exploratory and was not intended to be representative of the TEFL community in Thailand, mitigating limitations of the use of convenience and snowball sampling approaches, where it is suggested that this can limit representation of the data collected (Bryman, 2006). The length and depth of blog content varied significantly, ranging from blogs comprising a few short entries, to those with hundreds of postings. Using inductive content analysis, text was analysed and coding categories emerged empirically, allowing for key themes, trends and concepts to be identified and subsequently incorporated in to the survey design.

Research phase two enabled a positivistic flavour to be brought in to the research, allowing for a larger quantity of data to be obtained than would be possible through qualitative means (Bryman, 2008). Surveys were administered online using e-mail and social-media links as methods of distribution taking convenience and snowball approaches, where existing contacts forwarded the survey to their acquaintances. Internet connectively allowed for the surveys to reach a large sample both demographically and geographically, with almost immediacy, beneficial due to research time constraints and the geographical nature of TEFL tourism. Whilst it can be argued that the use of convenience and snowball sampling approaches can limit representation of the data collected (Bryman, 2006), this was not viewed as a concern due to the exploratory nature of the research.

The majority of the survey consisted of closed-questions, most of which were multiple choice or Likert-style, based on research findings from phase one. This allowed for easier quantification and analysis. A total of 567 responses were obtained enabling suggested generalisations to be made regarding the TEFL population in Thailand, although this is not considered large enough to be representative. Responses were obtained from TEFL teachers 
operating in a variety of geographical locations throughout Thailand. After the process of data cleansing, data were analysed using SPSS software. As a result of the majority of data being nominal, it was not possible to make any general assumptions about the population that the sample was drawn from, such as normal distribution and equal variance (Ho, 2006; Pallant, 2007; Privitera, 2015). Therefore, the majority of statistical tests undertaken were nonparametric (Pallant, 2007).

The chi-square test was frequently used throughout the analysis process enabling exploration of the variables associated with different types of TEFL tourists. Once significant relationships were determined these were used within a logarithmic regression model to predict teacher type based upon the associated variables (Privitera, 2015), determining if the respondent was a member of the associated typology. Based upon general themes identified in research phase one, the TEFL typology was formulated inclusive of the following categories; leisure-minded TEFLer; philanthropy-minded TEFLer; career-minded TEFLer; expatriate-minded TEFLer. An index was created for each teacher type based upon these themes and respondents were classified according to their highest score. It was these classifications that were then subsequently examined within the logistic regression tests.

\section{$\underline{\text { TEFL Tourism Characteristics }}$}

There were a number of common characteristics between TEFL tourists. They tended to be older than their volunteer tourist colleagues (who are typically aged 18-22) (TRAM, 2008; Tomazos and Butler, 2009; Wearing, 2001), with the majority (58\%) being between the ages of 22-30. Similarly to volunteer tourists (Gecko et al, 2009; Tomazos and Butler, 2009), the majority of TEFL tourists were single. There were five dominant nationalities; British, American, South Africa, Irish, Australian, correlating with the accepted nationalities 
indicated on many of the TEFL agency websites. Eighty-five percent of TEFL tourists were qualified to degree level or above. Again, this is in line with volunteer tourism (Birdwell, 2011; Tomazos and Butler, 2009). Of this number, $24 \%$ stated that they were continuing students, the most common of whom were studying teaching-focused qualifications (47\%). It is a legal requirement for all foreign teachers to obtain the correct Thai visa, whether they undertake their work in the capacity of tourism or are a long-term expatriate. To undertake paid employment the TEFL teacher requires a non-immigrant B visa, granted on receipt of their degree and TEFL certificates, a criminal record clearance, an official recommendation letter from the education institution in Thailand where they are based and information in relation to the contract or term of employment. Similarly, volunteers must obtain a nonimmigrant $\mathrm{O}$ visa by providing official recommendation from the organisation in Thailand at which they are based and information on the term of voluntary work. (Royal Thai Embassy, 2016). Numerous respondents, however, did not meet the legal requirements (45.1\%). In support of Methanonpphakhun and Deocampo's (2016) findings, many respondents (15\%) indicated that the process was complicated and the most common reasons for illegal employment were paperwork delays (32.8\%) and lack of organisation by the school or the agency responsible (32.4\%). The extent of illegal employment in Thailand make examination of the size, scope and impacts of the TEFL industry extremely difficult due to a proportion of the teaching community being 'hidden' through illegal employment (Kirkpatrick, 2012; Punthumasen, 2007).

There are concerns about the skillset held by TEFL tourists. Puntheumasen (2007) states that many foreign teachers in Thailand are 'out of field', meaning that they do not hold qualifications relevant to teaching or the subject being taught, which has been known to 
lead to poor quality of work undertaken (Benson and Wearing, 2012; Guttentag, 2009). This was supported in the data collected, where $54 \%$ of respondents were deemed insufficiently qualified to work as a TEFL teacher in Thailand based on their lack of university degree, teaching and English qualifications. This lack of skills was a particular concern amongst bloggers, evidenced through the following remarks;

'It may seem crazy that you may be working with [foreign] teachers who have taught English for 20 or more years and struggle to put together a grammatically correct sentence' I'm not a very good writer I don't claim to be, I don't have structure and sometimes my Grammar is bad! I'm sure people read this and think 'eh she teaches English?' lol' [sic] The limited skillset possessed by TEFL tourists was further emphasised by a lack of previous experience. Similarly to those undertaking a volunteer tourism placement (Lepp, 2008), under half of TEFL tourists (47\%) had prior teaching experience. Unlike volunteer tourism however, where not all roles require specialist skills, teaching skills and subject knowledge are integral to the quality of the education provided by the TEFL tourist.

In contrast to volunteer tourism (Gecko et al, 2009), most TEFL tourists (75\%) were not teaching as part of a gap year experience, despite Thailand being rated the most popular gap year destination (ABTA, 2013). Similarly to research focusing on the lengths of volunteer tourism placements (Callanan and Thomas, 2005; Gecko et al, 2009; Keese, 2011), there was a strong variance between the duration of TEFL tourism. In support of the figures presented by the International TESOL Association (2014), who found that $50 \%$ of TEFL teachers teach for up to one year, this research found that $46 \%$ of respondents taught for a duration between one week to one year and the most common length of a TEFL placement was 1-2 
years. Respondents were predominantly situated in a major city $(44.3 \%)$ or a rural area (40.8\%), whilst $10.8 \%$ were located close to the beach.

As previously noted, the main differentiation between TEFL tourism and volunteer tourism is that the majority of TEFL tourists are paid for their services (81\%). Official salaries ranged from $£ 70-£ 2775$ per month, with an average salary of approximately $f 700$. Many TEFL tourists (19\%) were also entitled unofficial salaries via expenses which included free accommodation or a housing allowance (65\%), food (24\%), travel reimbursement (30\%), visas and work permits (13\%) and insurance (9\%). There was however a strong theme of inequality of pay demonstrated by TEFL tourists, invoking notions of inequality, imperialism and neo colonialism. Remarks included;

'I felt terrible and very uncomfortable for being paid much more than many of my Thai colleagues - who were just as, if not more, knowledgeable as me.' [sic]

'[I was frustrated by] the sheer hatred from teachers due to the extremely disproportionate rate of pay. New Thai teachers make 7,000. We started out at 5 times that with no clue what we were doing. They didn't think it was fair and some of them were mad at us for it.'

On average TEFL tourists taught for 16-20 hours each week in a range of educational institution types categorised as government-funded schools (64.2\%), privately-funded schools (45\%) and language institutions (22.3\%). Secondary level teaching was the most common amongst TEFL teachers in Thailand, closely followed by junior level (30.5\%), infants (14.1\%), pre-school (11.8\%), university (9.9\%) and adult classes (6.3\%). Over half of the respondents (54.9\%) indicated that they taught across more than one student level. 
There was a strong theme of commodification demonstrated, with almost half (49\%) of respondents organising their TEFL placement via an agency. For those who paid an initial fee to an agency, the average amount was approximately $f 550$. This is significantly lower than the average cost of $f 2000$ to undertake a volunteer tourism trip (TRAM, 2008). In contrast to the volunteer tourism sector however, a quarter of TEFL tourists did not pay an official initial fee, instead the agency took a percentage of their salary each month, although the amount was largely unknown. It was suggested that some TEFL teachers are unaware of these payments as noted below;

'I wondered why my friends salary was so much lower than mine so she investigated only to find out that she was paying a percentage of her salary to the organisation each month. What an absolute RIP off! If it went to the school or to someone in Thailand I could maybe have some empathy, but it didn't- it went straight back to the US based organisation that placed her there!' [sic]

Whilst it can be argued unethical that TEFL teachers may be paying money to an agency without their knowledge, this remark also highlights ambiguities with regards to where the money spent ends up. This is a concern that has been highlighted within the literature addressing volunteer tourism (e.g. Benson and Wearing, 2012; Tomazos and Butler, 2009), although to date there is no broad solution to this problem. Like volunteer tourism (e.g. Benson and Wearing, 2012; Tomazos and Butler, 2009; Wearing and McGehee, 2013), TEFL organisations are diverse, wide ranging and often ambiguous, thus making it difficult to understand the motives and intentions of each individual agency.

\section{Motivations}


Key motivational themes for becoming a TEFL tourist can be broadly organised into aspects relating to travel and tourism, life experiences such as skill development or new experiences, and destination-specific motivations such as the Thai food or culture. Over half (52\%) of TEFL tourists strongly agreed that travel and tourism was a motivating factor, thus emphasising the links between TEFL and tourism. For some, TEFL teaching was secondary to the travel experience;

'Teaching was always part of my life plan, maybe not as a career, but at least as an excuse to travel'

'There was no way I could just 'travel' indefinitely. So I headed to the USA to work on a summer camp, then to Chiang Mai, Thailand to teach English'

This notion is supported by Methanonpphakhun and Fernandez Deocampo (2016), who found in their research that most foreign teachers were not motivated as a result of their love of teaching, but rather to travel, for education or to start a new life. Furthermore, Punthumasen (2007) described foreign TEFL teachers in Thailand as tourists, who bring with them the negative connotations associated with lack of relevant experience, skills and qualifications.

There are many motivations which can be situated beneath the travel and tourism umbrella. Motivations exhibited by respondents such as having the opportunity to visit the beach (23\%) and to become involved with the nightlife activities (20\%) demonstrate clear links with the common sun, sea and sand motivations frequently associated with package holidays (Poon, 1993) and nightlife tourism (Calafat et al, 2010; Tutenges, 2013). Those motivated to become a TEFL teacher in Thailand because they want to immerse themselves in to the Thai culture (85\%) also demonstrate links with cultural tourism, whether this be 
through the consumption of products such as sites or monuments (Bonink, 1992; Munsters, 1994), or experiencing cultural aspects such as religion, ethnic traditions, linguistics and learning about Thai heritage through the community engagement (Maclntosh and Goeldner, 1986).

Motivations thematically classified as life experiences, defined as any endeavor which facilitates experiences that the TEFL teacher may not have otherwise experienced, tended to be akin with the concept of lifelong learning, fostering the continuous development and improvement of knowledge and skills needed for employment and personal fulfilment throughout life (Broomhall et al, 2010; Falk et al, 2012). This included motivations to enhance their CV (58\%), develop teaching skills (65\%) and trial teaching as a career (63\%), demonstrating connections with educational tourism (Ritchie et al, 2003). Prominent motivations to aid skill development have also been demonstrated in a number of studies addressing the volunteer tourism industry (e.g. Coghlan and Fennell, 2009; Daldeniz and Hampton, 2011; Soderman and Stead, 2008), although these tend to be generic skills, as opposed to the specific teaching skills acquired through the practice of TEFL. A further $70 \%$ were motivated to learn more about themselves.

Supporting the connection made between TEFL tourism and philanthropy, the majority of respondents $(65 \%)$ in research phase two identified that they were motivated by prospects of 'doing something good', however as suggested by Lyons and Wearing in their study of volunteer tourism (2012), this may not necessarily be indicative of their primary motivations. Whilst it is important to remember that TEFL teachers can hold multiple motivations, whether altruistic or selfish, simultaneously (Hustinx, 2011; Tomazos and Butler, 2010), it can has also been suggested that there is no such things as an unselfish 
tourist. In fact, Wearing and McGehee (2013a) claim that volunteer tourists are likely to disguise their selfish motivations behind their altruistic façade.

Motivations such as the reduced cost of living (62\%), a slower pace of life (45.3) and the ability to easily secure employment in Thailand (35\%) can be attributed to destination specific motivations. Thailand is also home to a sizeable sex tourism industry, encompassing both casual endeavors such as prostitution or sex shows (Kusy, 2001) and opportunities for long-term romantic engagements (Ruenkaew, 1998; Sims, 2012). For some, these lifestyle choices were motives for becoming a TEFL teacher in Thailand, with $6 \%$ of TEFL tourists motivated by sex tourism-based nightlife opportunities and $16 \%$ motivated by prospects of a romantic relationship with a native Thai. Henkel et al (2006) emphasise the appeal of Thailand to international visitors as a result of the sightseeing opportunities, friendly people, food, nightlife and entertainment, whilst the UNWTO (2012) state that the majority of tourists visit in pursuit of sun, sea, sand and nature. These claims are in part represented within the data collected for this research, with $85 \%$ motivated by the Thai culture, $62 \%$ by the weather, $43 \%$ by the food, $23 \%$ by the beaches and $20 \%$ by the nightlife.

\section{TEFL Typology}

There were four dominant positions adopted by TEFL teachers in Thailand that centered around the concepts of leisure, philanthropy, career and expatriatism. The typological models created through undertaking a series of four logistic regression tests are presented in the diagram below which shows the strength of the influence that each variable had on the model. The variables in grey were noted as being common factors amongst respondents in that group, but did not directly impact on the strength of the model. 


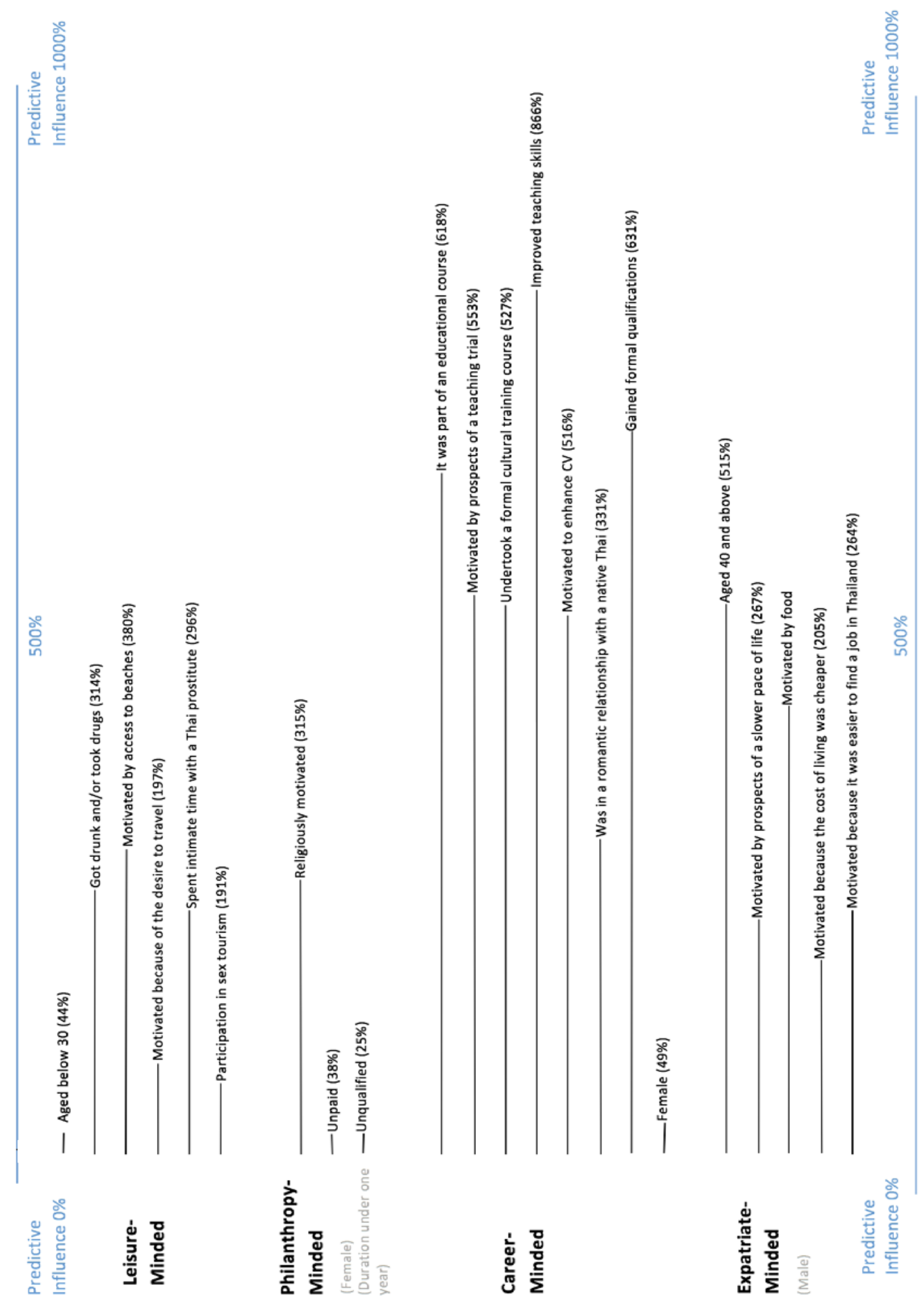


The majority of respondents demonstrated attributes associated with all positions throughout their TEFL experience, demonstrating that they do not neatly fit in to any one category, although one may be more prominent than another. This supports the notion of role ambiguity (Lyons and Wearing, 2008), where it is unclear who the TEFL tourist is and how to define them based on the ability to possess multiple motivations simultaneously (Hustinx, 2001; Tomazos and Butler, 2010).

Some scholars have suggested that rather than categorising tourists de facto, it is best to position them along a continuum (e.g. Hustinx, 2001; Tomazos and Butler, 2010). However this is viewed inappropriate as this would not account for the shifting roles (Mustonen, 2005; Sin, 2009) of TEFL teachers. Based on blogger comments during the qualitative data analyisis, it is suggested TEFL teachers shift roles depending on the day of the week, geographical location or the company they are in. For example, a TEFL teacher may be philanthropy or career-minded Monday to Friday when in the local community, and leisureminded on the weekend when they travel to the tourist areas. This rhetoric was demonstrated through the following remarks;

"Friday night involved a trip to the beach sipping on "magic" [mushroom] drinks, entering a different universe and staying up to watch the sunrise... It felt bizarre that once Monday came we'd have to be back being responsible adults taking care of children's English education.'

'[TEFL teaching is] like being in college again. During the day, you all focus on learning the basics of english teaching. At night, it's a shit show. Late nights on the beach drinking beer, exploring different bars \& restaurants all over Phuket, gossip about the latest hookups and other wild, Real World-esque shenanigans.'[sic] 
This shifting of roles demonstrates behavioural inversion (de Oliveira and Paiva, 2007), where bloggers and respondents demonstrated behaviour that they would not usually exhibit in their educational environment. Effectively, they appeared to adapt their identities depending upon space and context (Malam, 2004), and whether they had the constraints of teaching responsibilities confining them to moderate their behaviour accordingly (Redmon, 2003). For opportunities outside of the community within which they teach TEFL tourists are able to be transported away from the restraints of their everyday life into states of abandon (Tutenges, 2013).

The first two teacher types, the leisure-minded TEFLer and the philanthropy-minded TEFLer, largely correspond with existing volunteer tourism typologies that categorise tourists according to their motivation. Similarly to Brown and Morrison's (2003) vacation-minded and Daldeniz and Hampton's (2011) volunTOURISTs the leisure-minded TEFLer tends to be travel-orientated. They are motivated by leisure opportunities including beach and nightlife tourism. They are likely to drink alcohol and take drugs as part of their TEFL experience and it is common that they have some involvement with the sex trade, ranging from casual attendance of sex shows to spending intimate time with a prostitute. This group often consists of tourists aged below 30 .

Likewise, the philanthropy-minded TEFLer corresponds with Brown and Morrison's (2003) volunteer-minded and Daldeniz and Hampton's (2011) VOLUNtourists. This teacher-type is often religiously motivated. They may be on a short-term, unpaid placement and without the formal requirements usually needed to work as a TEFL teacher in Thailand. They are often female. This is the smallest group of TEFL teachers, perhaps due to philanthropy not being the primary motivation (Lyons and Wearing, 2012), or due to the TEFL tourist putting 
on an altruistic façade in attempt to disguise their true motivations (Wearing and McGehee, 2013a). There is also the concept of philanthrocapitalism (Edwards, 2009; Hero, 2001; McAlister and Ferrell, 2002), where philanthropy is used as a means to enhance ones competitive identity, thus indicating that although intentions may appear altruistic, they are in fact selfish. As such, many respondents who indicated career-based intentions were instead classified as career-minded as a result of this being their most dominant position, indicating that the concept of philanthropy is not a dominant one amongst TEFL teachers.

Approximately half of TEFL tourists were classified as career-minded TEFLers, making this the largest group. This teacher-type largely corresponds with Ritchie et al's (2003) description of educational tourism, where education and learning are important parts of the TEFL experience. It was argued previously that the education sphere takes two approaches; the education to the TEFL teacher and the education provided by the TEFL teacher. The career-TEFLer centers around the former. This perhaps fits best with Ritchie et al's (2003) education first tourist, although it is not necessarily limited only to university, college or school tourism as they suggest. Rather it appears to be more akin with existential (Kolb, 1984), transformative (Coghlan and Gooch, 2011; Mezirow, 1991) or lifelong learning (Broomhall et al, 2010; Falk et al, 2012) that may be facilitated through a formal educational institution or may take place through a process of experience and reflection. The notion of learning amongst TEFL teachers as opposed to their students brings rise to question whether the respondents are too indeed students in their own regard, putting the concept of education into new light within the TEFL experience. Most career-minded TEFLers undertake formal study and qualifications as part of their experience, demonstrate improvement in their teaching skills and were motivated by the prospects of a trial teaching 
period before potentially commencing a teaching career in their home country or elsewhere and to enhance their CV. They were often female.

The expatriate-minded TEFLer consisted mainly of male TEFL tourists. The typological model demonstrated that the expatriate-minded TEFLer tends to be motivated by lifestyle prospects including food, the cost of living, job opportunities and the prospects of a slower pace of life than they would otherwise have in their home country. In line with Howard's (2009) research into the Thai expatriate community, these are predominantly over the age of 40 and in a relationship with a Thai native. The strong relationship between this teachertype and romantic relationships, coupled with the scale of the sex trade in Thailand, presupposes that a significant proportion of these TEFL tourists may be involved with the sex tourism paradigm of 'mail' or 'Thai' brides (e.g. Ruenkaew, 1998; Ryan, 2000; Sims, 2012). Although this was not specifically explored within this research, it is an area worthy of further investigation.

\section{Conclusion}

As a phenomena, TEFL tourism is a diverse, multifaceted and inter-disciplinary concept. Whilst the notion of educational tourism provides some lineage between the two industries of education and tourism, this paper presents new light on this relationship. In contrast to educational tourism as it has traditionally been known, the relationship between education and tourism is two dimensional, where the education need not only be received by the tourist, but the tourist also provides the education. This niche presents links with a number of tourism forms including cultural, philanthropic and package tourism. Demonstrating the strongest lineage however is the volunteer tourism industry, which to date has housed the majority of references to TEFL teaching outside the realms of teaching pedagogy. Whilst 
there may be some similarities, and there are most certainly lessons that can be learned from volunteer tourism, it has been demonstrated in this paper that TEFL tourism is a rather different entity in terms of remuneration, packaged products, characteristics and motivations.

This paper has introduced the concept of TEFL tourism, proposing an operational definition and typology of TEFL tourists. Rooted in the ambiguous concepts of tourism and TEFL, the TEFL tourism phenomenon however is subject to a level of complexity. Geographical and cultural contexts, surging globalisation, developing economies, the growing need for English teachers (British Council, 2014), lack of regulation and the differences across education systems all contribute to the TEFL tourism industry being broad and diverse in nature. As such, the proposed definition and typology, which is formed on the case-study basis of TEFL in Thailand, is intended not to be necessarily prescriptive of TEFL tourists across all countries, but rather as a basis from which contextualisation can occur depending on the unique circumstances of different geographical locations.

Similarly to the volunteer industry, until Wearing's first publication in 2001, which identified what a volunteer tourist was and what they did, there was little known about the industry. Subsequently, the following fifteen years have seen an emergence of research spanning various geographical locations, volunteer tourism types, the benefits and limitations and the commercialisation of the industry. The intention is that this preliminary research in to the TEFL tourism industry will act in a similar fashion, providing the ground work for a plethora of research to enable enhanced comprehension and sustainable management of the TEFL tourism industry worldwide. Areas worthy of further research include the linkages between 
TEFL tourism and backpacking and working holidays, the impacts of TEFL tourism and possibility of increased regulation and policy to better manage the industry.

\section{$\underline{\text { References }}$}

Abrams, I. (1979) The Impact of Antioch Education through Experience Abroad. Alternative Higher Education. 3 (3): 176-187.

Association of British Travel Agents. (2013) ABTA Reveals Top Gap Year Destinations and Provides Advice to British Teenagers Heading Overseas. http://abta.com/news-andviews/press-zone/abta-reveals-top-gap-year-destinations-and-provides-advice-to-britishteena (Accessed 23 June 2016).

Association of Internet Researcher. (2012) Ethical Decision Making and Internet Research. Recommendations from the AOIR Working Committee. http://aoir.org/reports/ethics2.pdf (Accessed 14 March 2016).

Banyai, M. and T. Glover. (2012) Evaluating Research Methods on Travel Blogs. Journal of Travel Research. 51 (3) 267-277.

Benson, A. and S. Wearing. (2012) Volunteer Tourism: Commodified Trend or New Phenomenon? In Controversies in Tourism. (Eds) O. Moufakkir and P.M. Burns Oxfordshire: CABI Publishing.

Bergman, E. (2013) Philanthropy for Tourism and Development in Africa. Global Giving Matters. 
http://www.synergos.org/globalgivingmatters/features/1301philanthropyfortourism.htm (Accessed 3rd March 2016).

Birdwell, J. (2011) This is the Big Society Without Boarders. Service International. London: Demos.

Bonink, C. (1992) Cultural Tourism Development and Government Policy. MA Dissertation: Rijksuniversiteit Utrecht.

Boorstin, D. (1964) The Image: A Guide to Psuedo-Events in America. New York: Harper and Row.

British Council. (2014) The British Council's Work in ELT Worldwide - An Introduction. Paper presented at TESOL 2014. International Convention and English Language Expo. Portland USA. 26-29 March.

Broomhall, S., T. Pitman, E. Majocha and J. McEwan. (2010) Articulating Lifelong Learning in Tourism: Dialogue Between Humanities Scholars and Travel Providers. Canberra: Australian Learning and Teaching Council.

Brown, S. and A. Morrison. (2003) Expanding Volunteer Vacation Participation-An Exploratory Study on the Mini-Mission Concept. Tourism Recreation Research. 28 (3)73-82. Brudney, J. (2000) The Effective Use of Volunteers: Best Practices for the Public Sector. Law and Contemporary Problems. 62 (4) 219-255.

Bryman, A. (2006) Integrating Quantitative and Qualitative Research: How Is It Done? Qualitative Research. 6 97-113. 
Butler, R. (1980) The Concept of a Tourist Area Cycle of Evolution: Implications for Management of Resources. Canadian Geographer. 24 (1) 5-12.

Calafat, A., N. Blay, M. Bellis, K. Hughes, A. Kokkevi, F. Mendes, B. Cibin, P. Lazarov, L. Bajcarova, G. Boyiadjis, M. Duch, M. Juan, C. Magalhares, R. Mendes, A. Pavlakis, I. Siamou, A. Stamos and S. Tripodi. (2010) Tourism, Nightlife and Violence: A Cross Cultural Analysis and Preventative Recommendations. Valencia: Martin Impresores.

Callanan, C. and S. Thomas. (2005) Volunteer Tourism: Deconstructing Volunteer Activities within a Dynamic Environment. In Niche Tourism: Contemporary Issues, Trends and Cases. (Eds) M. Novelli. Oxford: Butterworth-Heinemann.

Coghlan, A. and D. Fennell. (2009) Myth or Substance: An Examination of Altruism as the Basis of Volunteer Tourism. Annals of Leisure Research. 12 (3-4) 377-403.

Coghlan, A. and M. Gooch. (2011) Applying a Transformative Learning Framework to Volunteer Tourism. Journal of Sustainable Tourism. 19 (6) 713-728.

Creswell, W (2003) Research Design: Qualitative, Quantitative and Mixed Method Approaches. $2^{\text {nd }}$ ed. California: Sage Publications.

Daldeniz, B. and M. Hampton. (2011) VOLUNtourists versus volunTOURISTS: A True Dichotomy or Merely a Differing Perception? In Volunteer Tourism: Theoretical Frameworks and Practical Applications. (Eds) A. Benson. Oxon: Routledge.

de Oliveira, A. and V. Paiva. (2007) Vulnerability to HIV: Tourism and the Use of Alcohol and Other Drugs. Rev Saúde Pública. 41 (2) 1-6. 
Duncan, T., Scott, D. and Baum, T. (2012) The Mobilities of Hospitality Work: An Exploration of Issues and Debates. Annals of Tourism Research. 41 1-19.

Edwards, M. (2009) Why 'Philanthrocapitalism' is not the Answer: Private Initiatives and International Development. In: Doing Good or Doing Better: Development Policies in a Globalising World. (Eds) M. Lieshout and R. Went. The Hague: Scientific Council for Government Policy WRR.

Ellis, C. (2003) Participatory Environmental Research in Tourism-A Global View. Tourism Recreation Research. 28 (3) 45-55.

Falk, J., R. Ballantyne, J. Packer and P. Beckendoriff. (2012) Travel and Learning: A Neglected Research Area. Annals of Tourism Research. 39 (2) 908-927.

Gecko, Bradt Travel Guides and Lasso Communications. (2009) Volunteer Travel Insights Report. USA.

Goodwin, H., L. McCombes and C. Eckardt. (2009) Advances in Travel Philanthropy: Raising Money Through the Travel and Tourism Industry for Charitable Purposes. London: WTM Report.

Graddol, D. (2014) Five Megatrends Shaping the Future of TESOL. TESOL 2014 International Convention and English Language Expo. $27^{\text {th }}$ March.

Griffith, S. (2014) Teaching English Abroad: Talk your Way Around the World. $13^{\text {th }}$ ed. Oxford: Vacation Work.

Guttentag, D. (2009) The Possible Negative Impacts of Volunteer Tourism. International Journal of Tourism Research. 11 (6) 537-551. 
Henkel, R., P. Henkel, W. Agrusa, J. Agrusa and J. Tanner. (2006) Thailand as a Tourist Destination: Perceptions of International Visitors and Thai Residents. Asia Pacific Journal of Tourism Research. 11 (3) 269-287.

Hero, P. (2001) Giving back the Silicon Valley Way: Emerging Patterns of a New Philanthropy. New Directions for Philanthropic Fundraising. 32 47-58.

Ho, R. (2006) Handbook of Univariate and Multivariate data Analysis and Interpretation with SPSS. London: Taylor and Francis.

Hookway, N. (2008) 'Entering the Blogosphere': Some Strategies for Using Blogs in Social Research. Qualitative Research. 8 (1) 91-113.

Howard, R. (2009) The Migration of Westerners to Thailand: An Unusual Flow from Developed to Developing World. International Migration. 47 (2) 193-225.

Hustinx, L. (2001) Individualisation and New Styles of Youth Volunteering: An Empirical Investigation. Voluntary Action. 3 57-76.

International TESOL Association (2014) TESOL. http://www.tesol.org/ (Accessed 22 May 2016).

Keese, J. (2011) The Geography of Volunteer Tourism: Place Matters. Tourism Geographies. 13 (2) 257-279.

Kogar, T. (2014) We Change People's Lives: Commodification of English in Thailand. The New English Teacher. 8 (1) 142-161.

Kolb, D. (1984) Experiential Learning. Englewood Cliffs, NJ: Prentice Hall.

Kusy, F. (1991) Thailand. London: Cadogan. 
Lavankura, P. (2013) Internationalising Higher Education in Thailand: Government and University Responses. Journal of Studies in International Education. 17 (5) 663-676.

Leiper, N. (1979) The Framework for Tourism: Towards a Definition of Tourism, Tourist and the Tourism Industry. Annals of Tourism Research. 1 (4) 390-407.

Lepp, A. (2008) Discovering Self and Discovering Others Through the Taita Discovery Centre Volunteer Tourism Programme, Kenya. In Journeys of Discovery in Volunteer Tourism. (Eds) K. Lyons and S. Wearing. Wallingford: CABI.

Lyons, K. (2003) Ambiguities in Volunteer Tourism: A Case Study of Australians Participating in a J-1 Visitor Exchange Program. Tourism Recreation Research. 28 (3) 5-13.

Lyons, K. and S. Wearing. (2008) Volunteer Tourism as Alternative Tourism: Journeys Beyond Otherness. In Journeys of Discovery in Volunteer Tourism: International Case Study Perspectives. (Eds) K. Lyons and S. Wearing. Kings Lynn: CABI Publishing.

Lyons, K. and S. Wearing. (2012) Reflections on the Ambiguous Intersections between Volunteering and Tourism. Leisure Sciences. 34 (1) 88-93.

Maclntosh, R.W. and R. Goeldner. (1986) Tourism: Principles, Practices, Philosophies. New York: Wiley and Sons.

Malam, L. (2004) Performing Masculinity on the Thai Beach Scene. Tourism Geographies. 6 (4) $455-471$.

Matheison, A. and G. Wall. (1982) Tourism: Economic Physical and Social Impacts. USA: Longman House. 
McAlister, D. and L. Ferrell. (2002) The Role of Strategic Philanthropy in Marketing Strategy. European Journal of Marketing. 36 (5/5) 689-705.

Meged, J., B. Blichfeldt, L. Hansen and K. Hvass. (2014) Tourism Methodologies.

Frederiksberg: CBS Press.

Methanonppkakhun, S. and M. Fernandez Deocampo. (2016) Being an English Language Teacher: A Narrative Analysis of Foreign Teachers in Thailand. The New English Teacher. 10 (1) 1-19.

Mezirow, J. (1991) Transformative Dimensions of Adult Learning. San Francisco: Jossey-Bass.

Mostafanezhad, M. (2013) The Politics of Aesthetics in Volunteer Tourism. Annals of Tourism Research. 43 150-169.

Munsters, W. (1994) Cultuurtoerisme. Garant: Apeldoorn.

Mustonen, P. (2005) Volunteer Tourism: Postmodern Pilgrimage? Journal of Tourism and Cultural Change. 3 (3) 160-177.

Novelli, M., N. Morgan, G. Mitchell and K. Ivanov. (2015) Travel Philanthropy and Sustainable Development: The Case of the Plymouth-Banjul Challenge. Journal of Sustainable Tourism. DOI: 10.1080/09669582.2015.1088858.

Pallant, J. (2007) SPSS Survival Manual. A Step by Step Guide to Data Analysis Using SPSS for Windows. $3^{\text {rd }}$ ed. Sydney: Ligare.

Poon, A. (1993) Tourism Technology and Competetive Strategies. Oxon: CABI.

Porter, M. and M. Kramer. (2002) The Competitive Advantage of Corporate Philanthropy. Harvard Business Review. 80 (12) 56-68. 
Privitera, G. (2015) Statistics for the Behavioral sciences. $2^{\text {nd }}$ ed. London: Sage Publications.

Punch, K. (2014) Introduction to Social Research. Quantitative and Qualitative Approaches. $3^{\text {rd }}$ Ed. London: Sage Publications.

Puntheumasen, P. (2007) International Program for Teacher Education: Approach to Tackling Problems of English Education in Thailand. The $11^{\text {th }}$ UNESCO-APEID International Conference Reinventing Higher Education: Toward Participatory and Sustainable Development. 12-14 December. Bangkok.

Redmon , D. (2003) Playful Deviance as an Urban Leisure Activity: Secret Selves, SelfValidation, and Entertaining Performances. Deviant Behavior. 24 (1) 27-51.

Ritchie, B., N. Carr and C. Cooper. (2003) Managing Educational Tourism. Clevedon: Channel View.

Robinson, M. and M. Novelli. (2007) Niche Tourism: An Introduction. In Niche Tourism. (Eds) M. Novelli. London: Routledge.

Ruenkaew, P. (1998). Thai women in Germany: A study on Marriage Migration. Women's Studies. Bangkok: Thammasat University Press.

Ryan, C. (2000) Sex Tourism: Paradigms of Confusion? In Tourism and Sex. (Eds) S. Clift and S. Carter. London: Pinter.

Seale, C. (2012) Researching Society and Culture. $3^{\text {rd }}$ ed. London: Sage Publications.

Sims, J. (2012) Beyond the Stereotype of the 'Thai-Bride'. Visibility, Invisibility and Community. In Transnational Marriage. New Perspectives from Europe and Beyond. (Eds) K. Charsley. London: Routledge. 
Sin, H. (2009) Volunteer Tourism-“Involve me and I will Learn”? Annals of Tourism Research. 36 (3) 480-501.

Snee, H. (2013) Making Ethical Decisions in an Online Context: Reflections on Using Blogs to Explore Narratives of Experience. Methodological Innovations Online. 8 (2) 52-67.

Soderman, N. and S. Snead. (2008) Opening the Gap: The Motivation of Gap Year Travellers to Volunteer in Latin America. In Journeys of Discovery in Volunteer Tourism: International Case Study Perspectives. (Eds) K. Lyons and S. Wearing. Wallingford: Cabi.

Stainton, H. (2016) A Segmented Volunteer Tourism Industry. Annals of Tourism Research. $16256-258$.

Stainton, H. (2017) The 'Blogosphere' as a Platform for Interpretive Phenomenological Analysis: The Case of TEFL Tourism. Current Issues in Tourism. DOI 10.1080/13683500.2016.1271404.

Stainton, H. (2017) The Commodification of English Language Teaching in Tourism: A Sustainable Solution? [In press].

Stainton, H. and Iordanova, E. (2016) An Ethical Perspective for Tourism Researchers Using Blog Analysis as a Research Method. Paper presented at The $6^{\text {th }}$ ICOT Conference-New Challenges and Boundaries in Tourism: Policies, Innovations and Strategies. 29 June-2 ${ }^{\text {nd }}$ July. Stone, N. and J. Petrick. (2013) The Educational Benefits of Travel Experiences: A Literature Review. Journal of Travel Research. 52 (6) 731-744.

Tomazos, K. and R. Butler. (2009) Volunteer Tourism: Working on Holiday or Playing at Work? Tourismos: An International Multidisciplinary Journal of Tourism. 4 (4) 331-349. 
Tomazos, K. and R. Butler. (2010) The Volunteer Tourist as 'Hero'. Current Issues in Tourism. 13 (4) 363-380.

Tourism Research and Marketing. (2009) Volunteer Tourism: A Global Analysis. Arnhem: ATLAS Publications.

Tutenges, S. (2013) Stirring up Effervescence: An Ethnographic Study of Youth at a Nightlife Resort. Leisure Studies. 32 (3) 233-248.

United Nations World Tourism Organisation. (2012) Strategic Tourism Planning: National Tourism Development Plan (2012-2016). Thailand. $6^{\text {th }}$ UNWTO Executive Training Programme. Bhutan. 25-28 June.

Vainikka, V. (2014) Travel Agent Discourses of Mass Tourism: Beyond Stereotypes? Tourism Geographies. 16 (2) 318-332.

van't Klooster, E., J. van Wijk, F. Go and J. van Rekom. (2008) Educational Travel. The Overseas Internship. Annals of Tourism Research. 35 (3) 690-711.

Wearing, S. (2001) Volunteer Tourism: Experiences that make a Difference. Wallingford: Cabi.

Wearing, S. and N. McGehee. (2013a) International Volunteer Tourism. Integrating Travellers and Communities. Wallingford: $\mathrm{CABI}$.

Wearing, S. and N. McGehee. (2013b) Volunteer Tourism: A Review. Tourism Management. 38 120-130.

Weaver, D. (2014) Asymmetrical Dialects of Sustainable Tourism: Towards Enlightened Mass Tourism. Journal of Travel Research. 53 (2) 131-140. 